\title{
Deep venous thrombosis and pulmonary embolism in psychiatric settings
}

\author{
Els G. Van Neste \\ Ward Verbruggen \\ Mark Leysen \\ Psychiatric Hospital Sint-Amedeus, Antwerp \\ BELGIUM
}

\begin{abstract}
Background and objectives: Deep venous thrombosis and pulmonary embolism are serious, possibly life-threatening events which are often ignored in psychiatric settings. This article investigates which psychiatric patients are at increased risk of developing a venous thromboembolism. To our knowledge we are the first to perform a literature review of clinical studies relating venous thrombosis and pulmonary embolism to psychotropic drugs and mental disorders.

Methods: A Medline search for English studies using the appropriate search terms was performed. In addition, cross references of the relevant articles` literature references were considered. We withheld 12 observational studies, 29 case-reports and one review-article.

Results: We found evidence that low potency antipsychotic drugs like chlorpromazine and thioridazine, and clozapine for treatment of resistant schizophrenia have an increased risk of venous thromboembolism. There is no evidence that antidepressants, benzodiazepines or mood stabilizers have a similar effect. Also psychiatric conditions like physical restraint, catatonia and neuroleptic malignant syndrome are related to a higher incidence of deep venous thrombosis.

Conclusions: Limitations of the studies and hypotheses about underlying biological mechanisms are reviewed. The rationale for prophylactic measures is discussed and recommendations to prevent deep venous thrombosis and pulmonary embolism are given.
\end{abstract}

\section{Introduction}

Deep venous thrombosis (DVT) and pulmonary embolism (PE) are frequent illnesses with an annual incidence of more than 1 per 1000 persons and a mortality rate above $15 \%$ in the first 3 months after diagnosis ${ }^{1}$. Both illnesses have a common pathogenesis and are referred to as venous thromboembolism (VTE). Many studies about this subject have been performed in medical and 
surgical settings. In psychiatric settings this problem is often ignored.

Known risk factors for development of DVT and PE during medical and surgical hospitalisations include congenital factors (i.e. hereditary thrombophilia like Factor V Leiden, prothrombin deficiency...) and acquired factors (advanced age, obesity, former DVT or PE, surgery, trauma, neoplasms, heart-, kidney-, and bowel diseases, oestrogen hormone therapy, tamoxifen, dehydration, immobilisation...). These risk factors can induce the formation of a DVT by three mechanisms described as Virchow's triad: slowing down of the blood velocity, damage to the vessel wall and hypercoagulability $^{2}$.

The aim of this literature review is to examine if psychotropic medication or specific psychiatric conditions give a higher risk of developing DVT or PE. Moreover we aim to investigate the underlying biological mechanisms or risk factors and give recommendations to prevent DVT and PE in psychiatric patients.

\section{Method}

A Medline search (1956- march 2008), for English studies using a combination of the following Mesh terms: "Venous Thrombosis", "Pulmonary Embolism" "Psychotropic drugs", "Mental Disorders" was performed. In addition, cross references of the relevant articles` literature references were considered. For each study or case-report, we defined study design, authors, study group and control group (if present), diagnosis, risk factors, treatment and results. We withheld 12 observational studies, 29 case-reports and one review-article. Studies were classified ac- cording to their link with either psychotropic drugs (antipsychotic drugs, antidepressants, benzodiazepines and mood stabilizers) or psychiatric conditions (physical restraint, catatonia, neuroleptic malignant syndrome).

\section{Results}

\section{Psychotropic drugs}

The association between conventional antipsychotics and VTE was investigated in 8 observational studies, listed in Table $\mathrm{I}^{3-10}$. Two studies suggest a positive association between conventional antipsychotics and VTE but are inconclusive (due to small numbers of patients) $)^{3,8}$. The data of 5 out of 6 remaining observational studies from large databases support the association between antipsychotic drugs and VTE for conventional antipsychotics ${ }^{4,5,7,9-10}$. Especially low potency antipsychotics such as chlorpromazine and thioridazine and to a lesser extent high potency antipsychotics such as haloperidol show a strong association with $\mathrm{VTE}^{7,9}$. More specifically an increased risk has been observed with phenothiazines, butyrophenones and benzamides were found ${ }^{5,7,10}$. Only the study of Liperoti et al. didn't find an increased risk ${ }^{6}$. In this study, low doses of antipsychotic agents were in accordance with recommendations for use in elderly people but were substantially lower than those previously prescribed in the study of Zornberg et al. ${ }^{3}$. The risk for VTE was highest during the first few months of conventional antipsychotic drug use ${ }^{3}$. Psychiatric conditions as schizophrenia ${ }^{6}$, an acute psychotic episode $^{7,9,10}$, dementia ${ }^{6,10}$ and alcohol or substance misuse ${ }^{7}$ were often not included in the study. Only in the study of Parkin et $a l .{ }^{6}$ and Hamanaka et al. ${ }^{4}$ the study focused 
on patients with severe psychiatric conditions as schizophrenia and bipolar disorder.

Other risk factors and protective factors for VTE were controlled in all studies by excluding them. Immobilisation as a risk factor was eliminated by excluding patients with an acute psychotic episode that can require fixation and sedation ${ }^{7,9,10}$, hospitalised patients ${ }^{5}$ and patients with low cognitive and daily functioning ${ }^{6}$. In all the studies, the diagnosis of DVT or PE was confirmed by objective standards such as dopplerultrasonography, ventilation perfusion scintigraphy, CT scan or autopsy ${ }^{3-10}$.

Two retrospective studies and 11 case reports highlighted the association between clozapine and VTE (Table II) ${ }^{11-23}$. Patients using regular doses of clozapine for treating resistant schizophrenia seem to have an increased risk to develop VTE in the first months of clozapine treatment ${ }^{12,15-20,23}$. Also, more men developed VTE during clozapine treatment although the prescription and reporting rate seems to be similar for both sexes ${ }^{12}$. The diagnosis was confirmed with appropriate technical investigations or autopsy in all studies ${ }^{11-23}$.

On the association between VTE and other atypical antipsychotic drugs, 4 casereports (Table II $)^{24-27}$ and 3 previously mentioned studies ${ }^{4-6}$ were found. The study of Hamanaka et al. was based on small numbers (4 patients) ${ }^{4}$ and Parkin et al. ${ }^{9}$ didn't find an increased risk. Only Liperoti et al. found a mild increased risk for atypical antipsychotic drugs ${ }^{6}$.

The literature review revealed one case report of fluoxetine ${ }^{28}$ and one of escitalopram $^{29}$ in association with VTE. In the previously mentioned studies of Ray et al., Zornberg et al., Parkin et al. and Lacut et al. (Table I) $^{5,7,9,10}$, only the study of Parkin et al. found an increased risk (odds ratio of 4.9
(95\% CI: 1.1 -22.5) for current use of antidepressants ${ }^{9}$. Recently, a nested case-control study, based on the United Kingdom General Practice Research database, found that amitriptyline, particularly at high doses, conferred an increased risk of VTE (odds ratio of $1.7(95 \% \text { CI 1.2-2.4) })^{30}$.

There were no relevant studies found on benzodiazepines.

The only relevant study about mood stabilisers showed an excess mortality by pulmonary embolism in 405 bipolar and 92 unipolar patients who attended the same outpatient lithium clinic for up to 30 years ${ }^{31}$.

\section{Psychiatric conditions}

The literature search revealed three psychiatric conditions with an increased risk of DVT or PE: physical restraint, catatonia, neuroleptic malignant syndrome (Table III) ${ }^{32-45}$.

In the English literature we found 6 cases of patients who developed a DVT or PE during physical restraint, listed in Table III $^{32-35}$. Physical restraint was usually applied in a suspine position with a waist belt or fourpoint restraint of the wrists and ankles. PE during physical restraint covered all age categories but was mainly present in men. The duration of restraint was long, between 3 to 13 days. In most of the cases risk factors other than physical restraint for VTE were present, with exception of the case report of Laursen et al. ${ }^{35}$. In two cases, the patients were complaining of chest pain or respiratory difficulties for several days, ascribed to anxiety or psychosis, before the correct diagnosis was made ${ }^{32,35}$. Two patient collapsed shortly after the restraints were removed $^{32,34}$ and one patient died 24 hours after removal of the restraints ${ }^{33}$. Antipsychotic medication was often given to sedate the patient during restraint. 


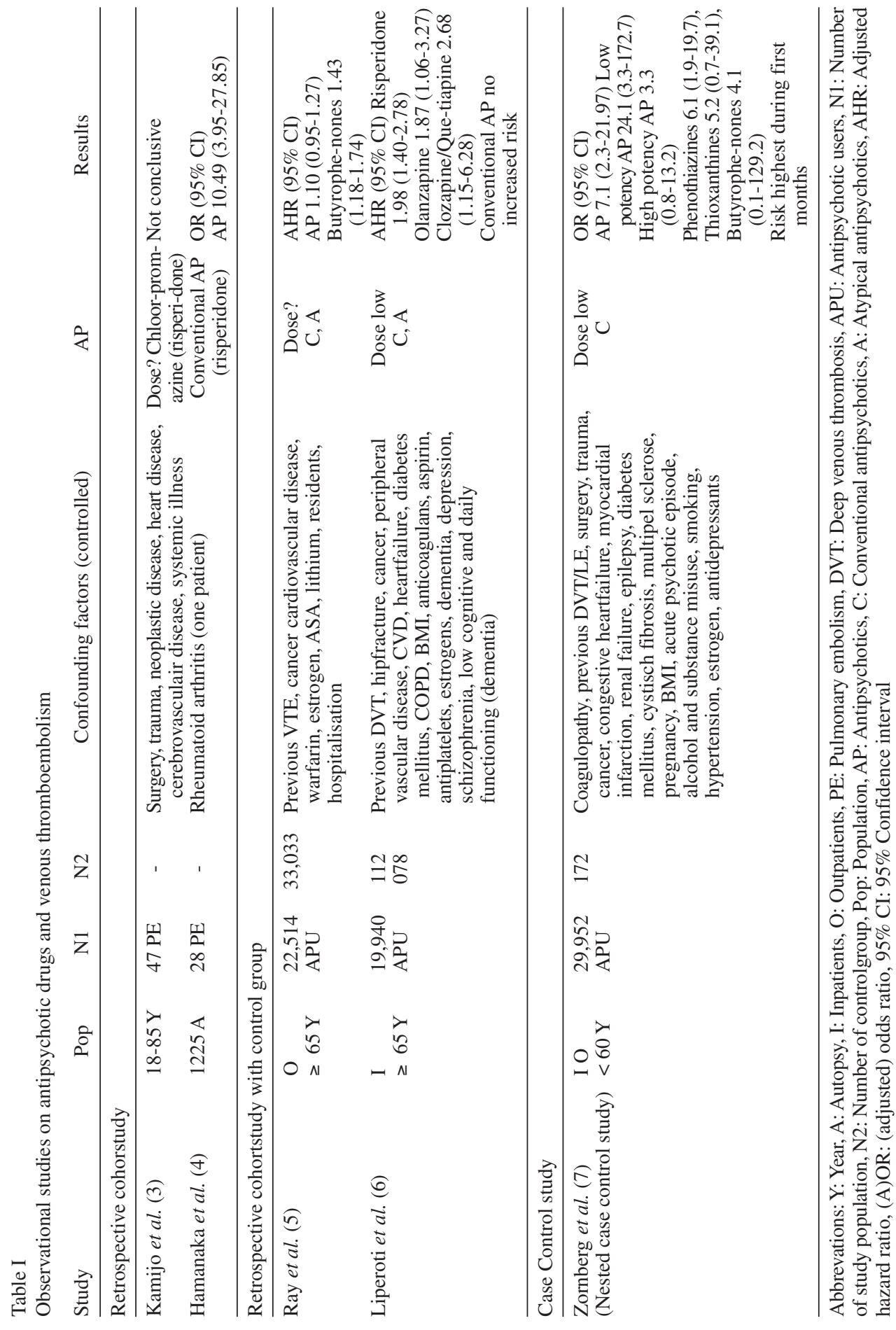




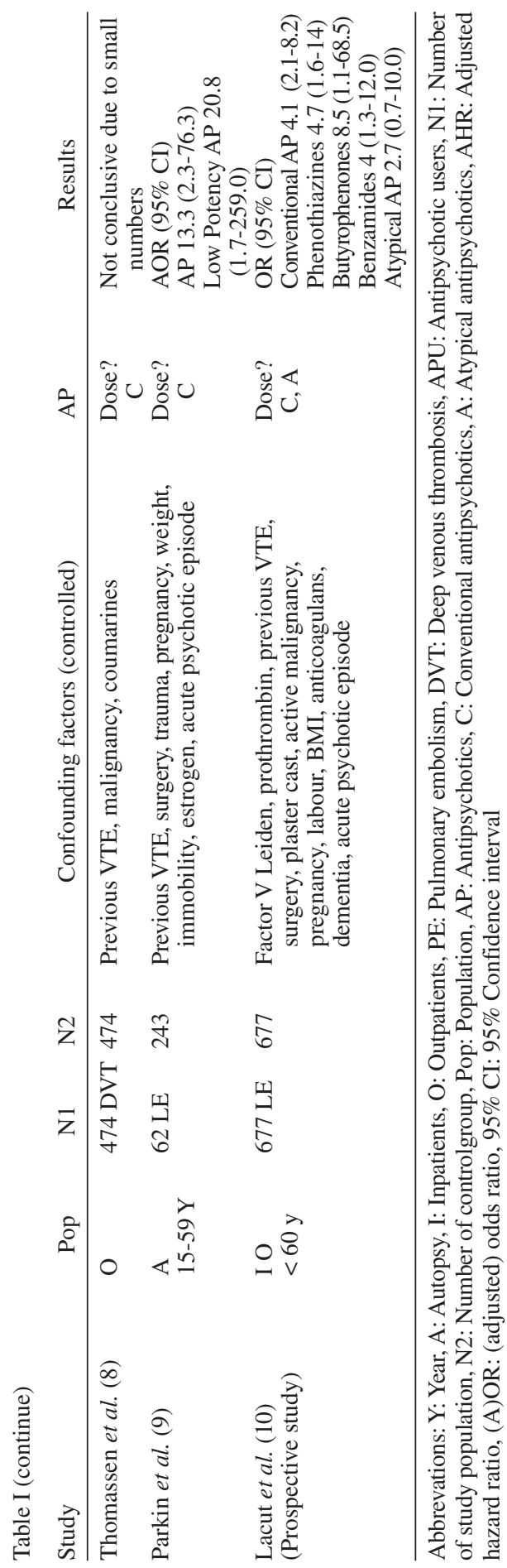

Five case reports and one review of 20 autopsy case-reports of PE in severe catatonia with psychomotor retardation are shown in Table III ${ }^{36-41}$. Immobility and refusal of fluids were always present as risk factors. The study of McCall et al. ${ }^{36}$ suggested death from PE would occur after the second week of catatonic symptoms and often occurred without warning. But in the case-report of $\mathrm{Woo}^{41}$, PE was diagnosed during the first week of catatonia. Antipsychotic drugs, antidepressants and benzodiazepines were given shortly before or during the catatonic state.

Six cases of patients who died from a PE during neuroleptic malignant syndrome have been described (Table III $)^{42-45}$. Neuroleptic malignant syndrome is characterized by severe rigidity, fever, altered mental status and autonomic dysfunction. Rhabdomyolysis was sometimes present in the reported cases.

In all case-reports the diagnosis of VTE was confirmed with appropriate technical investigations or autopsy ${ }^{32-45}$.

\section{Discussion}

\section{Limitations}

The data demonstrate an association between antipsychotic drugs and VTE for conventional antipsychotics ${ }^{4,5,7,9-10}$ and clozapine ${ }^{11-23}$. The risk was highest during the first few months of antipsychotic drug use and also applies to less affected patients.

Most observational studies on conventional antipsychotics were based on large databases with a control group $5,6,7,9,10$ and one study was a prospective study ${ }^{10}$. However, most studies were not mentioning the dose of antipsychotic drugs and concomitant use of medication ${ }^{3,4,5,8,9,10}$. Most risk 


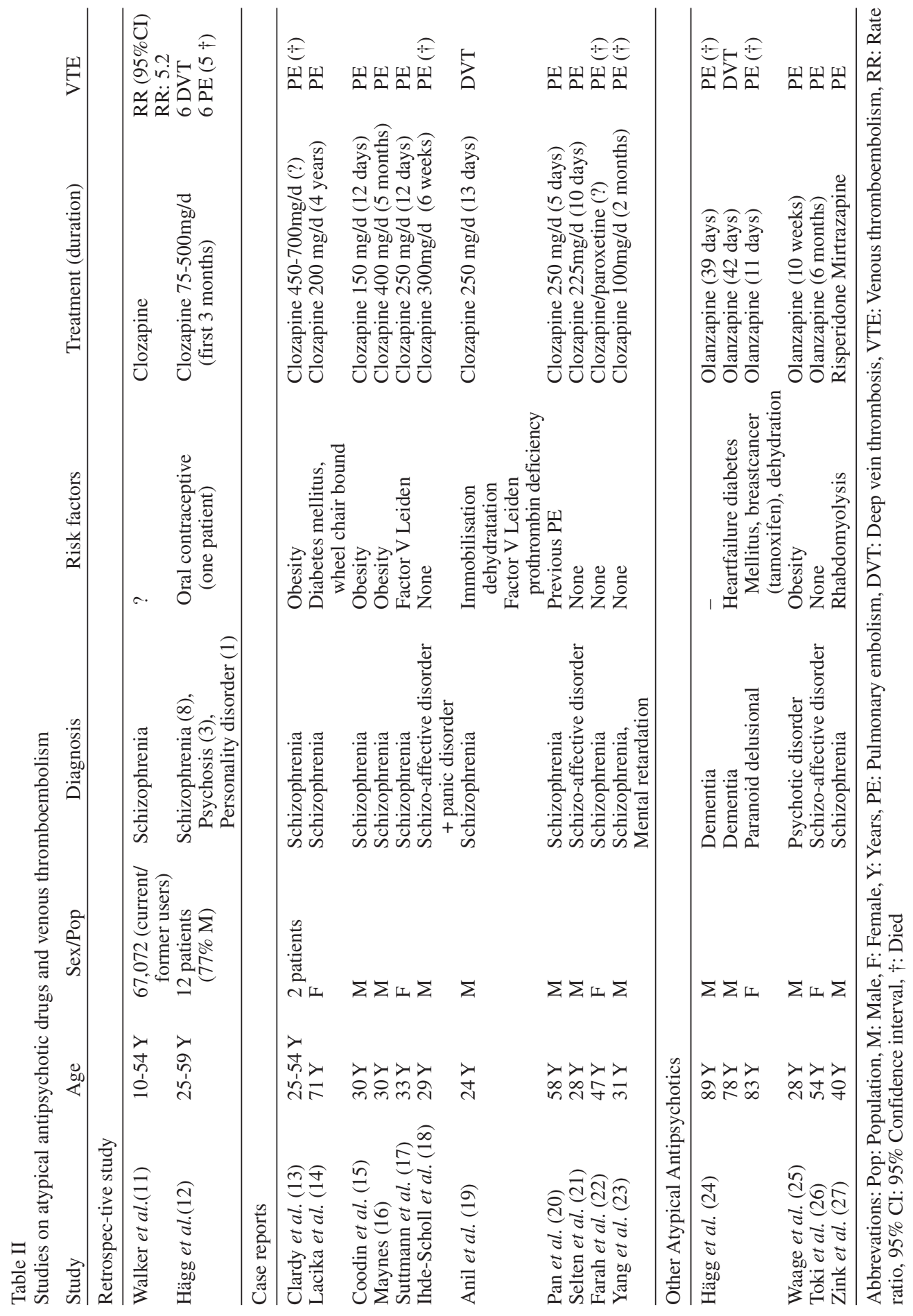




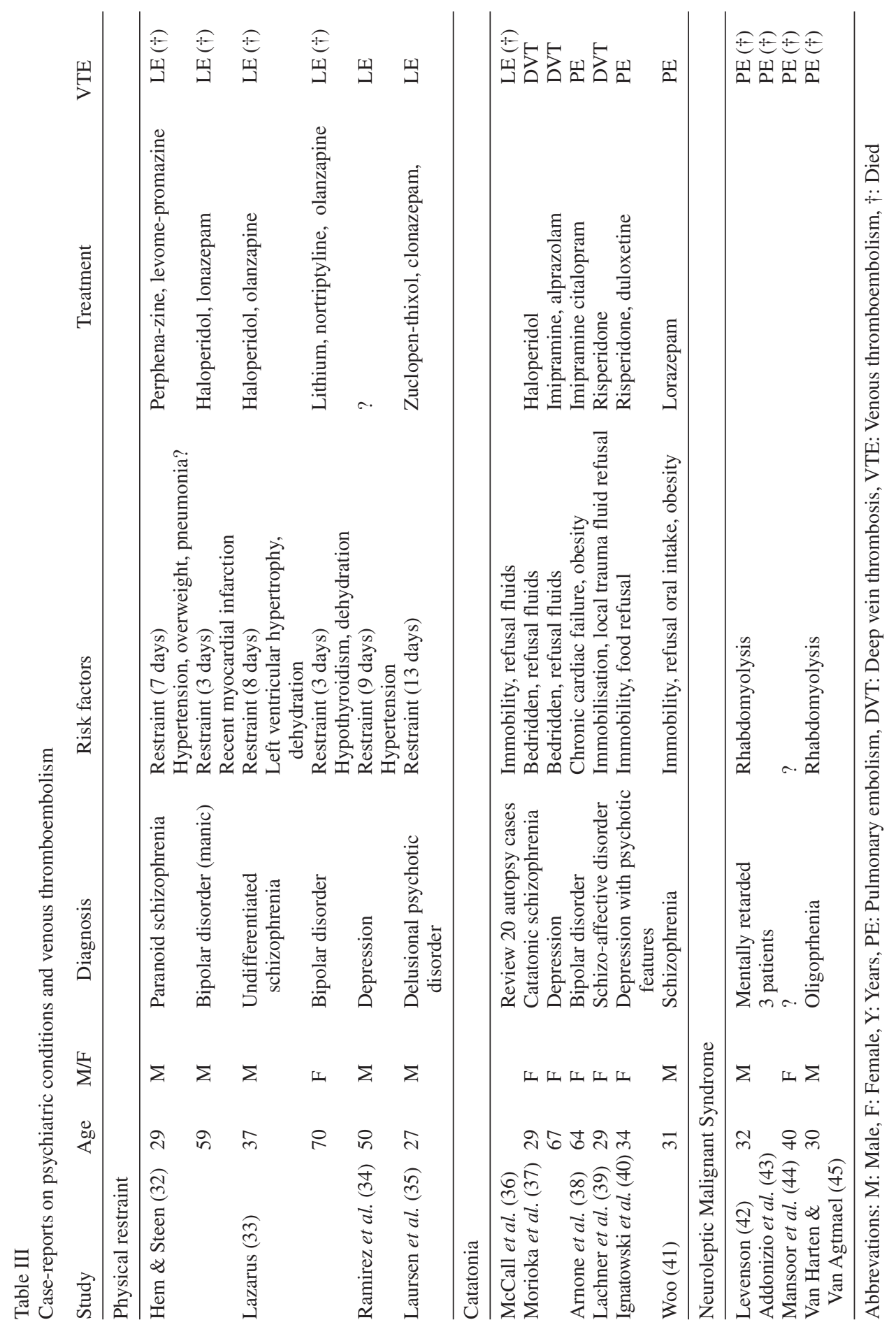


factors were controlled in the studies but only the recent study of Lacut et al excluded the congenital risk factors, factor V Leiden and prothrombin deficiency ${ }^{10}$. Although special attention was paid to avoid recall bias, it can not be completely ruled out.

Both retrospective studies on clozapine were not controlling other risk factors for $\mathrm{VTE}^{11,12}$. In most case-reports other risk factors were present but not examined or mentioned completely ${ }^{13-23}$. Further observational studies should ideally include a control group.

Findings on atypical antipsychotic drugs other than clozapine were few and discordant ${ }^{4-6}$.

There is only few or no evidence that antidepressants, benzodiazepines or mood stabilizers give an increased risk of VTE ${ }^{5,7,9,10,28-31}$.

Physical restraint, catatonia and neuroleptic malignant syndrome predispose to VTE with possibly fatal outcome. These findings are based on numerous case-reports (Table III) ${ }^{32-45}$. The common denominator in all three conditions is immobility. The case reports perform an important role in highlighting the risk of immobility in these psychiatric conditions. Other risk factors for developing VTE were not examined completely. Antipsychotic drugs had often been used in this patients although stopped in catatonia and neuroleptic malignant syndrome. This can be a confounding factor. Observational studies might be difficult to design for severe catatonia and neuroleptic malignant syndrome since they are relatively rare conditions.

There are two important limitations of this literature review: language bias and diagnosis bias. Exclusion of papers published in non-English languages might have limited the total number of cases available for inclusion.
Secondly, pulmonary embolism is often misdiagnosed as sudden cardiac death. Ten of 27 cases of fatal pulmonary embolism were diagnosed in psychiatric patients only at autopsy ${ }^{46}$. This makes it possible that some cases of PE are missed and without autopsy are ascribed to other fatal conditions.

\section{Underlying biological mechanisms}

Serveral underlying mechanisms have been proposed to explain the association between antipsychotic drugs and VTE. Sedation induced by antipsychotic drugs, can increase venous stasis. Hypercaogulability via an enhanced aggregation of platelets with conventional antipsychotics has been suggested in previous studies 47,48 or via hyperprolactinemia in an indirect pathway more recently ${ }^{49}$. Another hypothesis is the increased levels of lupus anticoagulant and anticaridiolipin antibodies induced by conventional antipsychotic agents and clozapine $^{50,51}$. Finally, hyperhomocysteinemia was also suggested as a plausibel underlying mechanism but is probably more related to the psychiatric disorder itself $f^{52,53}$.

Immobilisation is regarded as an important risk factor for surgical and bedridden patients ${ }^{54}$ but also for healthy persons on long distances air travels ${ }^{55}$ or in persistent sitting position $^{56}$. In conditions like physical restraint, severe catatonia and neuroleptic malignant syndrome immobilisation, causing slowing down of the bloodstream, seems the common risk factor for the development of VTE. Additional risk factors for VTE inherent to the specific psychiatric conditions are: heavy resistance during physical restraint situations (damage to the vessel wall), lack of fluid intake in severe catatonia (hypercoagulability) and fever and rhabdomyolysis in the 
neuroleptic malignant syndrome (hypercoagulability) ${ }^{57}$. Three factors can cause delay in medical attention. Firstly, the patient may due to his illness not be able to communicate leg pain from DVT or chest pain or respiratory difficulties from $\mathrm{PE}^{39}$. Secondly, there is a risk that these physical complaints are ascribed to anxiety or psychosis and are not taken seriously ${ }^{32,35}$. Thirdly, PE can occur without warning signs and sometimes patients collapsed when ambulation was restarted which may activate silent cloths ${ }^{33}$.

The studies on antipsychotic drugs ruled out the influence of immobility by exclusion. During physical restraint, severe catatonic states or neuroleptic malignant syndrome, antipsychotic drugs are often used before or during the illness. But in catatonia and neuroleptic malignant syndrome antipsychotics are mostly stopped.

\section{Prophylaxis and treatment}

DVT and PE are life threatening illnesses. Prophylactic measures for VTE in medical and surgical settings are physical excercise, placement of elastic stockings, use of pneumatic compression and administration of subcutaneous heparin ${ }^{58}$. This review raises the question if patients on antipsychotic agents or during physical restraint, severe catatonic state or neuroleptic malignant syndrome should receive prophylactic measures against VTE.

Although VTE prophylaxis for all patients taking antipsychotic drugs is inappropriate, we have to consider the fact that the risk of VTE increases significantly if several risk factors are present at the same time ${ }^{59}$. Screening patients for additional risk factors of DVT and PE seems advisable to identify those patients that would benefit from prophylaxis. Prophylaxis proposed by some authors to prevent VTE in patients during prolonged restraint or with severe catatonia, range from a higher awarness of VTE, conducting frequent physical examinations, physical excercise, until anticoagulation ${ }^{34,37-40}$. Some authors suggest anticoagulation therapy during immobility due to neuroleptic malignant syndrome for al such patients ${ }^{42,45}$. There is one report on a prophylaxis scheme in a mental hospital in the Czech Republic but this is not based on scientific evidence ${ }^{60}$. Until there is more evidence from prospective observational and randomized controlled studies recommendations based on prophylactic measures taken in medical and surgical settings ${ }^{58}$ seems appropriate.

If a psychiatric patient is identified as having an increased risk for VTE the following prophylactic measures should be considered. Firstly, avoidance of strict bedrest or immobility and an increased amount of exercise is for most patients sufficient but often ignored. Also sufficient hydration is of importance. Secondly, complaints such as swelling, pain or discolouring of the leg, chest pain or dyspnoea merit special attention. Conducting physical examinations focusing on this complaints is essential. Further technical investigations as Doppler ultrasound of the lower extremity to diagnose DVT or ventilation-perfusion scan or spiral CT of the chest to diagnose for PE is necessary. Thirdly, the implementation of other deep venous thrombosis prophylactic measures (i.e. placement of elastic stockings, use of pneumatic compression or administration of subcutaneous heparin) should be considered in high risk patients. We consider patients taking antipsychotics combined with multiple other risk factors, physical restraint for long periods, persistent immobility due to severe catatonia and neuroleptic malignant syndrome at high risk for VTE. 


\section{Conclusion}

Psychiatric patients taking conventional antipsychotic drugs or clozapine, under physical restraint or suffering from severe catatonia or neuroleptic malignant syndrome seem to have an increased risk to develop deep venous thrombosis and pulmonary embolism which are potentially life-threatening events. A double blind study in the psychiatric population is needed in order to refine the subgroups of our patients who would benefit from DVT prophylaxis.

\section{References}

1. Goldhaber SZ, Visani L, De Rosa M. Acute pulmonary embolism: clinical outcomes in the International Cooperative Pulmonary Embolism Registry (ICOPER). Lancet 1999 Apr 24; 353(9162): 1386-1389.

2. Lowe GD. Virchow's triad revisited: abnormal flow. Pathophysiol Haemost Thromb 2003; 33: 455-457.

3. Kamijo Y, Soma K, Nagai T. Acute massive pulmonary thromboembolism associated with risperidone and conventional phenothiazines. Circ J 2003; 67: 46-48.

4. Hamanaka S, Kamijo Y, Nagai T. Massive pulmonary thromboembolism demonstrated at necropsy in Japanese psychiatric patients treated with neuroleptics including atypical antipsychotics. Circ J 2004; 68: 850-852.

5. Ray JG, Mamdani MM, Yeo EL. Antipsychotic and antidepressant drug use in the elderly and the risk of venous thromboembolism. Thromb Haemost 2002 Aug; 88(2): 205-209.

6. Liperoti R, Pedone C, Lapane KL. Venous thromboembolism among elderly patients treated with atypical and conventional antipsychotic agents. Arch Inter Med 2005; 165: 2677-2682.

7. Zornberg G, Jick H. Antipsychotic drug use and risk of first-time idiopathic venous thromboembolism: a casecontrol study. Lancet 2000; 356: 1219-1212.

8. Thomassen R, Vandenbroucke JP, Rosendaal FR. Antipsychotic medication and venous thrombosis. Br J Psychiatry 2001; 179: 63-66.
9. Parkin, L, Skegg DC, Herbison GP. Psychotropic drugs and fatal pulmonary embolism. Pharmacoepidemiol Drug Saf 2003; 12: 647-652.

10. Lacut K, Le Gal G, Couturaud F, Cornily G, Leroyer C, Mottier D, Oger E. Association between antipsychotic drugs, antidepressant drugs and venous thromboembolism: results from the EDITH case-control study. Fundam Clin Pharmacol 2007 Dec; 21(6): 643-650.

11. Walker AM, Lanza LL, Arellano F. Mortality in current and former users of clozapine. Epidemiology 1997; 8: 671-677.

12. Hägg S, Spigset O, Söderström TG. Association of venous thromboembolism and clozapine. Lancet 2000; 355: 1155-1156.

13. Clardy J, Gale RH. Mortality risk and clozapine. Am J Psychiatry 1995 Apr; 152(4): 651.

14. Lacika S, Cooper JP. Pulmonary embolus possibly associated with clozapine treatment. Can J Psychiatry 1999 May; 44(4): 396-397.

15. Coodin S, Ballegeer T. Clozapine therapy and pulmonary embolism. Can J Psychiatry 2000 May; 45(4): 395.

16. Maynes D. Bilateral pulmonary embolism in a patient on clozapine therapy. Can J Psychiatry 2000 Apr; 45(3): 296-297.

17. Suttmann I, Dittert S, Landgraf R, Schulze J, Folwaczny C. Clozapine and sudden death. Lancet 2000 Mar 4; 355(9206): 842-843.

18. Ihde-Scholl T, Rolli ML, Jefferson JW. Clozapine and pulmonary embolus. Am J Psychiatry 2001; 158: 499500 .

19. Anil AE, Ozkan B, Ulusahin A. Venous thromboembolism and clozapine: an association unresolved. Gen Hosp Psychiatry 2003 Jan-Feb; 25(1): 59-60.

20. Pan R, John V. Clozapine and pulmonary embolism. Acta Psychiatr Scand 2003; 108: 76-77.

21. Selten JP, Büller H. Clozapine and venous thromboembolism: further evidence. J Clin Psychiatry 2003 May; 65(5): 60.

22. Farah RE, Makhoul NM, Farah RE, Shai MD. Fatal venous thromboembolism associated with antipsychotic therapy. Ann Pharmacother 2004 Sep; 38(9): 1435-1438.

23. Yang TY, Chung KJ, Huang TL, Kung CT. Massive pulmonary embolism in a young patient on clozapine therapy. J Emerg Med 2004 Jul; 27(1): 27-29. 
24. Hägg S, Tatting P, Spigset O. Olanzapine and venous thromboembolism. Int Clin Psychopharmacol 2003; 18: 299-300.

25. Waage IM, Gedde-Dahl A. Pulmonary embolism possibly associated with olanzapine treatment. Br Med J 2003; 327: 1384.

26. Toki S, Morinobu S, Yoshino A, Yamawaki S. A case of venous thromboembolism probably associated with hyperprolactinemia after the addition of olanzapine to typical antipsychotics. J Clin Psychiatry 2004 Nov; 65(11): 1576-1577.

27. Zink M, Knopf U, Argiriou S, Kuwilsky A. A case of pulmonary thromboembolism and rhabdomyolysis during therapy with mirtazapine and risperidone. J Clin Psychiatry 2006 May; 67(5): 835.

28. Momen MN, Sebaston S, Buckley P, Ga A. Paradoxical reaction to fluoxetine. Psychosomatics 2003; 44: 259-260.

29. Kurne A, Ertugrul A, Anil Yagcioglu AE, Yazici KM. Venous thromboembolism and escitalopram. Gen Hosp Psychiatry 2004 Nov-Dec; 26(6): 481-483.

30. Jick SS, Li L. Antidepressant use and risk of venous thromboembolism. Pharmacotherapy 2008 Feb; 28(2): 144-150.

31. Kallner G, Lindelius R, Petterson U, Stockman O, Tham A. Mortality in 497 patients with affective disorders attending a lithium clinic or after having left it. Pharmacopsychiatry 2000 Jan; 33(1): 8-13.

32. Hem E, Steen O, Opjordsmoen S. Thrombosis associated with physical Restraints. Act Psychiatr Scand 2000; 103(1): 73-75, discussion 75-76.

33. Lazarus A. Physical restraints, thromboembolism, and death in 2 patients. J Clin Psychiatry 2001; 62(3): 207208.

34. Ramirez M, Imaz H, Ruiz JH. Thromboembolism after physical restraint Acta Psychiatr Scand 2001; 104(6): 473-474.

35. Laursen SB, Jensen TN, Bolwig, T. Deep venous thrombosis and pulmonary embolism following physical restraint. Acta Psychiatr Scand 2005; 111(4): 324-327.

36. McCall WV, Mann SC, Shelp FE. Fatal pulmonary embolism in the catatonic syndrome: two case reports and a literature review. J Clin Psychiatry 1995; 56: 21-25

37. Morioka H, Nagatomo I, Yamada K. Deep venous thrombosis of the leg due to psychiatric stupor. Psychiatry Clin Neurosci 1997; 51: 323-326.

38. Arnone D, Hansen L, Davies G. Pulmonary embolism and severe depression. Am J Psychiatry 2002; 159: 873-874.
39. Lachner C, Sandson NB. Medical complications of catatonia: a case of catatonia-induced deep venous thrombosis. Psychosomatics 2003 Nov-Dec; 44(6): 512-514.

40. Ignatowski MD, Samtokh SB, Rueve M. Pulmonary embolism as a complication of major depressive disorder with catatonic features: A case report. Psychiatry 2007; 4(6): 51-56.

41. Woo BK. Basal Ganglia calcification and pulmonary embolism in catatonia. J Neuropsychiatry Clin Neurosci 2007 Fall; 19(4): 472-473.

42. Levenson JL. Neuroleptic malignant syndrome. Am J Psychiatry 1985; 143: 1137-1145.

43. Addonizio G, Susman VL, Roth SD. Neuroleptic malignant syndrome: review and analysis of 115 cases. Biol Psychiatry 1987; 22: 1004-1020.

44. Mansoor GA, Corbin DO, Edwards CN. Neuroleptic malignant syndrome among acute psychiatric admissions in Barbados. West Indian Med J 1992; 41: 15-18.

45. Van Harten PN, Van Agtmael MA. Complete anticoagulation for treatment of neuroleptic malignant syndrome? Am J Psychiatry 1995; 152: 1103-1104.

46. Vandenbroucke JP, Bertina RM, Holmes ZR, Spaargaren C, van Krieken JH, Manten B, Reitsma PH. Factor V Leiden and fatal pulmonary embolism. Thromb Haemost 1998; 79: 511-516.

47. Boullin DJ, Woods HF, Grimes RP, Grahame-smith DG. Increased platelet aggregation responses to 5-hydroxytryptamine in patients taking chorpromazine. Br J Clin Pharmacol 1975; 2: 29-35.

48. Orr MW, Boullin DJ. The relationship between changes in 5-HT induced platelet aggregation and clinical state in patientstreated with fluphenazine. Br J Clin Pharmacol 1976; 3: 925-928.

49. Wallaschofski H, Eigenthaler M, Kiefer M et al. Hyperprolactinemia in patients on antipsychotic drugs causes ADP-stimulated platelet activation that might explain the increased risk for venous thromboembolism: pilot study. J Clin Psychopharmacol 2003; 23: 479-483.

50. Canoso RT, De Oliveira RM, Nixon RA. Neuroleptic-associated autoantibodies. A prevalence study. Biol Psychiatry 1990; 27: 863-870.

51. Davis S, Kern HB, Asokan R. Antiphospholipid antibodies associated with clozapine treatment. Am J Hematol 1994; 46: 166-167.

52. Susser E, Brown AS, Klonowski E, Allen RH, Lindenbaum J. Schizophrenia and impairedhomocysteine metabolism: a possible association. Biol Psychiatry 1998; 44: 141-143. 
53. Applebaum J, Shimon H, Sela BA, Belmaker RH, Levine J. Homocysteine levels in newly admitted schizophrenic patients. J Psychiatr Res 2004; 38: 413-416.

54. Kierkegaard A, Norgren, L, Olsson, CG. Incidence of deep vein thrombosis in bedridden non-surgical patients. Acta Med Scand 1987; 222: 409-414.

55. Scurr JH, Machin SJ, Bailey-Ling S. Frequency and prevention of symptomless deep-vein thrombosis in long-haul flights: A randomised trial. Lancet 2001; 357: 1485-1489.

56. Beasley R, Raymond N, Hill S. Thrombosis: the 21 st century variant of venous thromboembolism associated with immobility. Eur Respir J 2003; 21: 374-376.

57. Bailes JE. Current treatment of thromboembolic events in neurosurgical patients. Perspectives of neurological surgery 1990; 1: 150-151.

58. Geerts WH, Pineo GF, Heit JA et al. Prevention of venous thromboembolism: the Seventh ACCP Conference on antithrombotic and thrombolytic therapy. Chest 2004 Sept; 126(3Suppl): S338-S400.

59. Rosendaal FR. Risk factors for venous thrombotic disease. Thromb Haemast 1999; 82: 610-619.

60. Malý R, Masopust J, Hosák L, Konupcíková K. Assessment of risk of venousthromboembolism and its possible prevention in psychiatric patients. Psychiatry Clin Neurosci 2008 Feb; 62(1): 3-8.

Address for correspondence:

Dr. Els G. Van Neste

Isabellalei 22

28180 Ekeren (Antwerp)

Belgium

Tel. +32 (0) 486409938

Fax +32 (0) 32333110

E-mail: elsvanneste@hotmail.com 